\title{
Efeito de diferentes fontes e solubilidades de fósforo no desenvolvimento e nutrição do capim Mombaça
}

\author{
Djalma Junior de Almeida Tavares Souza ${ }^{1}$, Saulo Oliveira Lima ${ }^{2}$, Cleiriany Pereira da Silva ${ }^{2}$, Gilson Araújo de \\ Freitas $^{2}$ \\ ${ }^{1}$ Universidade Federal da Paraíba - UFPB, PB; ${ }^{2}$ Universidade Federal do Tocantins - UFT, TO. E-mail: \\ araujoagro@hotmail.com
}

\section{Resumo}

O fósforo é primordial para as pastagens e a adubação combinada com fontes fosfatadas podem aumentar qualidade nutricional e produtiva do Mombaça. Diante disto, objetivou-se neste estudo avaliar as características morfológicas, produtivas e nutricionais do capim Mombaça submetido a combinações de fontes de fósforo solúvel e natural. O delineamento experimental foi o inteiramente casualizado, com dez tratamentos e quatro repetições. Os tratamentos consistiram de três fontes e seis combinações de fontes de fosforo equivalente a $90 \mathrm{~kg} \mathrm{ha}^{-1}$ de $\mathrm{P}_{2} \mathrm{O}_{5}$, sendo: Controle, Rejeito de rocha fosfática (RJ), Superfosfato triplo (ST), Yoorin Master 1 (YR), RJ + ST (70\% e 30\%), RJ + ST (50\% e 50\%), RJ + YR (70\% e 30\%), RJ + YR (50\% e 50\%), YR + ST (70\% e 30\%), YR + ST (50\% e 50\%). O capim Mombaça foi cultivado durante três cortes (60, 105 e 150 DAS). As combinações YR + ST (50\% e 50\%), YR + ST (70\% e 30\%) e RJ + YR (50\% e 50\%) proporcionaram resultados positivos para caracteres agronômicos e as fontes RJ, RJ + ST (50\% e $50 \%)$ e RJ + YR (50\% e 50\%) para teor de P. A adubação fosfatada, independentemente da fonte e mistura, propiciou incremento no capim Mombaça.

Palavras-chave: adubação fosfatada; cerrado; degradação de pastagem; Megatirsus maximus.

\section{Effect of different phosphorus sources and solubilities in mombaça grass development and nutrition}

\begin{abstract}
Phosphorus is primordial for pasture and fertilization combined with phosphate sources that can increase the nutritional and productive quality of Mombasa. With that, the objective of this study was to evaluate the morphological, productive and nutritional characteristics of Mombaça grass submitted to combinations of soluble and natural phosphorus sources. The experimental design was randomized with ten treatments and four replications. Controls consist of three sources and six combinations of phosphorus sources equivalent to $90 \mathrm{~kg} \mathrm{ha}^{-1}$ of $\mathrm{P}_{2} \mathrm{O}_{5}$, namely: Control, Phosphate Rock Tailings (RJ), Triple Superphosphate (ST), Yoorin Master 1 (YR), RJ + ST (70\% and 30\%), RJ + ST (50\% and 50\%), RJ + YR (70\% and 30\%), RJ + YR (50\% and $50 \%)$, YR + ST (70\% and 30$) \%)$, YR + ST (50\% and 50\%). Mombasa grass was grown in three cuts (60, 105 and 150 DAS). As combinations YR + ST (50\% and 50\%), YR + ST (70\% and $30 \%)$ and RJ + YR (50\% and $50 \%$ ) provided positive results for agronomic characters and as RJ, RJ + ST ( $50 \%$ and $50 \%$ ) and RJ + YR ( $50 \%$ and $50 \%)$ for the $\mathrm{P}$ content. The phosphate addition, the source reduction and the mixture increased the Mombaça grass.
\end{abstract}

Keywords: phosphate fertilization; cerrado; pasture degradation; Megatirsus maximus.

\section{Introdução}

A maior parte das forrageiras cultivadas no Estado do Tocantins é representada por gramíneas do gênero Urochloa. No entanto, suas pastagens têm sofrido grande redução com a continuidade dos anos de exploração do solo, por causa da falta de manejo adequado, como calagem, gessagem, capacidade de suporte 
adequado e principalmente pela falta de adubação fosfatada no estabelecimento e manutenção das pastagens. A forrageira Megathyrsus maximus cv. Mombaça vem tomando espaço na região em substituição às pastagens de Urochloa. No entanto, os baixos níveis de fósforo disponível no solo, seja pela condição natural seja pela redução proveniente da falta de manejo e reposição, tem feito com que algumas cultivares de Megathyrsus maximus, tais como Mombaça, Tanzânia, entre outras, não tenha obtido sucesso (COSTA et al., 2017).

O fósforo é um dos elementos que mais limitam o crescimento e desenvolvimento das plantas, está entre os elementos mais importantes para o vigor, desenvolvimento e aspectos nutricionais das culturas (MALAVOLTA, 1980). Em razão do fósforo ser um nutriente limitante na produção e pela sua deficiência nos solos brasileiros, a prática de adubação assume papel fundamental para o estabelecimento, manutenção e nutrição das pastagens (CARNEIRO et al., 2017). Vários estudos têm comprovado a importância da adubação fosfatada para o adequado estabelecimento e a manutenção das pastagens cultivadas nos solos brasileiros (COSTA et al., 2017; MELO et al., 2018a; TEIXEIRA et al., 2018).

A possibilidade do emprego de fosfatos naturais e/ou rejeito de rocha, com baixo custo de produção tem sido enfatizada como alternativa viável para o suprimento da necessidade de fósforo (MELO et al., 2018b). Contudo, um dos problemas na utilização de fosfatos naturais é a baixa eficiência no primeiro ano de plantio, em relação às fontes solúveis em água, de forma que a mistura de fontes solúveis com fosfatos naturais pode ser uma opção interessante. São poucas as informações do capim Mombaça no Estado do Tocantins, necessitando de mais estudos para determinar suas exigências com fontes fosfatadas sintéticas e de rejeito de rocha isoladas ou em combinação.

As fontes de fósforo podem ser divididas em solúveis, pouco solúveis e insolúveis (KORNDÖRFER et al., 1999). As primeiras, quando adicionadas ao solo, aumentam rapidamente a sua concentração na solução, mas têm sua eficiência diminuída ao longo do tempo devido aos processos de adsorção ou fixação que ocorrem na maioria dos solos brasileiros (FERNANDES, 2006). Já os fosfatos naturais, que são pouco solúveis em água, se dissolvem lentamente na solução do solo e tendem a aumentar a disponibilidade do fósforo para as plantas ao longo do tempo. Segundo Oliveira et al. (2015) os fosfatos naturais, em geral, apresentam baixa eficiência agronômica para culturas de ciclo curto e anual, porém, em longo prazo, sua eficiência tende a aumentar, sendo seu efeito residual geralmente maior que as fontes solúveis.

$O$ requerimento de grandes quantidades de fosfatos na construção da fertilidade dos solos brasileiros, e a ausência de reservas abundantes de rochas fosfatadas de boa qualidade no País, associados ao elevado custo dos fertilizantes, justificam estudos para aperfeiçoar a eficiência no uso isolados ou combinados de adubos fosfatados de diferentes solubilidades. A produção de fertilizantes fosfatados gera grandes quantidades de rejeito (pó de rocha) com quantidades consideráveis de fósforo, a utilização destes rejeitos na agropecuária pode ser uma das soluções para este problema (TOSCANI; CAMPOS, 2017). O rejeito de rocha apresenta como características a composição multielementar e a capacidade de solubilização lenta, que são apropriadas para a utilização em sistemas de produção de pastagens, como o Mombaça, principalmente em solos tropicais degradados, com respostas positivas em culturas anuais, cultivos florestais e pastagens (VAN STRAATEN, 2006).

Diante disto, objetivou-se com este trabalho avaliar o efeito do uso de fontes de fósforo de diferentes solubilidades nas características morfológicas e nutricionais do Megathyrsus maximus cv. Mombaça no cerrado tocantinense.

\section{Material e Métodos}

O trabalho foi realizado em casa de vegetação localizada na Estação Experimental da Universidade Federal do Tocantins, Campus de Gurupi, localizado a $11^{\circ} 43^{\prime} 46^{\prime \prime}$ S e $49^{\circ} 04^{\prime} 04^{\prime \prime}$ W, com $280 \mathrm{~m}$ de altitude. O clima, segundo Thornthwaite, é do tipo $A w$, úmido com moderada deficiência hídrica, com precipitação anual média de $1.400 \mathrm{~mm}$.

O experimento foi conduzido em vasos de polietileno com capacidade de $21,2 \mathrm{dm}^{3}$, preenchidos com solo coletado a $20 \mathrm{~cm}$ de profundidade em Latossolo Vermelho Amarelo distrófico com as características descritas na Tabela 1. A forrageira utilizada foi Megathyrsus maximus cv. Mombaça. Na semeadura foram colocadas 15 sementes por vaso e após a 
germinação foram realizados desbastes deixando cinco plantas.

Tabela 1. Análise Química e Textural do solo utilizado no experimento

\begin{tabular}{|c|c|c|c|c|c|c|c|c|c|}
\hline \multirow[t]{2}{*}{$\mathrm{Ca}$} & $\mathrm{Mg}$ & $\mathrm{Al}$ & $\mathrm{H}+\mathrm{Al}$ & $\mathrm{CTC}(\mathrm{T})^{1}$ & $\mathrm{CTC}(\mathrm{t})^{2}$ & \multirow{2}{*}{$\begin{array}{l}\mathrm{V}^{3} \\
\%\end{array}$} & $P$ & K & $\mathrm{Zn}$ \\
\hline & & ---- & $\mathrm{oldm} \mathrm{m}^{-3}$ & t & 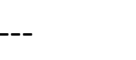 & & \multicolumn{3}{|c|}{-------mg dm³----- } \\
\hline 0,8 & 0,2 & 0,0 & 1,5 & 2,60 & 1,1 & 42,31 & 1,8 & 39,0 & 0,5 \\
\hline \multicolumn{2}{|c|}{$\mathrm{pH}$} & Mat & gânica & \multicolumn{6}{|c|}{---ontura g.kg ${ }^{-1}$} \\
\hline $\mathrm{H}_{2} \mathrm{O}$ & $\mathrm{CaCl}_{2}$ & & & \multicolumn{2}{|c|}{ Areia } & \multicolumn{2}{|c|}{ Silte } & \multicolumn{2}{|c|}{ Argila } \\
\hline 6,2 & 5,6 & \multicolumn{2}{|c|}{2,0} & \multicolumn{2}{|c|}{440,0} & \multicolumn{2}{|c|}{110,0} & \multicolumn{2}{|c|}{450,0} \\
\hline
\end{tabular}

${ }^{1}$ CTC total; ${ }^{2}$ CTC efetiva; ${ }^{3}$ Saturação por base.

O delineamento experimental foi inteiramente casualizado, com dez tratamentos e quatro repetições. Os tratamentos foram constituídos por fontes de fósforo de diferentes solubilidades e suas combinações, sendo: 1 . Rejeito de rocha fosfática - RJ (contendo $8 \%$ de $\mathrm{P}_{2} \mathrm{O}_{5}$ total, $11,3 \%$ de $\mathrm{CaO}$ e $4,68 \%$ de $\mathrm{Fe}_{2} \mathrm{O}_{3}$, oriundo da região de Irecê-BA), 2. Superfosfato triplo -ST $\left(41 \% \mathrm{P}_{2} \mathrm{O}_{5}, 7\right.$ $-12 \%$ de $\mathrm{Ca}), 3$. Yoorin Master $1-\mathrm{YR}$ (17,5\% de $\mathrm{P}_{2} \mathrm{O}_{5}$ total, $13 \%$ de $\mathrm{P}_{2} \mathrm{O}_{5}$ solúvel em ácido cítrico, $18 \%$ de $\mathrm{Ca}, 7 \%$ de $\mathrm{Mg}, 0,1 \%$ de $\mathrm{B}, 0,05 \%$ de $\mathrm{Cu}$, $0,3 \%$ de $\mathrm{Mn}, 10 \%$ de Si e $0,55 \%$ de $\mathrm{Zn}), 4$. RJ + ST (70\% e $30 \%), 5 . \mathrm{RJ}+\mathrm{ST}(50 \%$ e $50 \%), 6 . \mathrm{RJ}+\mathrm{YR}$ (70\% e $30 \%), 7 . R J+Y R(50 \%$ e $50 \%), 8 . Y R+S T$ (70\% e 30\%), 9.YR + ST (50\% e 50\%) e 10. Controle. Para avaliação das características nutricionais foram considerados as fontes RJ, ST, YR, RJ+ST $(50 \%+50 \%), R J+Y R(50 \%+50 \%), Y R+S T$ $(50 \%+50 \%)$ e controle. As doses de fósforo foram obtidas conforme recomendações de Vilela et al.
(2007) adaptado, a partir dos resultados obtidos na análise de solo. A dose padrão de fósforo foi fixado em $90 \mathrm{~kg} \mathrm{ha}^{-1}$.

O nitrogênio (sulfato de amônio) e o potássio (cloreto de potássio) foram fornecidos em cobertura, na dose de $100 \mathrm{~kg} \mathrm{ha}^{-1}$ de $\mathrm{N}$ e $100 \mathrm{~kg}$ $\mathrm{ha}^{-1} \mathrm{~K}_{2} \mathrm{O}$ (VILELA et al., 2007), dividida em três parcelas. A primeira cobertura foi realizada aos 20 dias e as demais aos sete dias após o primeiro e o segundo corte.

A irrigação foi realizada por aspersão, com vazão de $3500 \mathrm{~L}$ hora $^{-1}$, com duração de 30 minutos dia ${ }^{-1}$, o que corresponde a uma chuva de $4 \mathrm{~mm}$ diários, totalizando uma precipitação 1400 $\mathrm{mm}$ anuais, quantidade suficiente para garantir o desenvolvimento da forrageira. Os dados de temperatura e umidade relativa do ar e precipitação durante o período do experimento estão apresentados na Figura 1.

Figura 1. Temperatura, umidade relativa do ar e precipitação no período de maio a outubro. Fonte: Boletim meteorológico da estação UFT- Gurupi-TO.

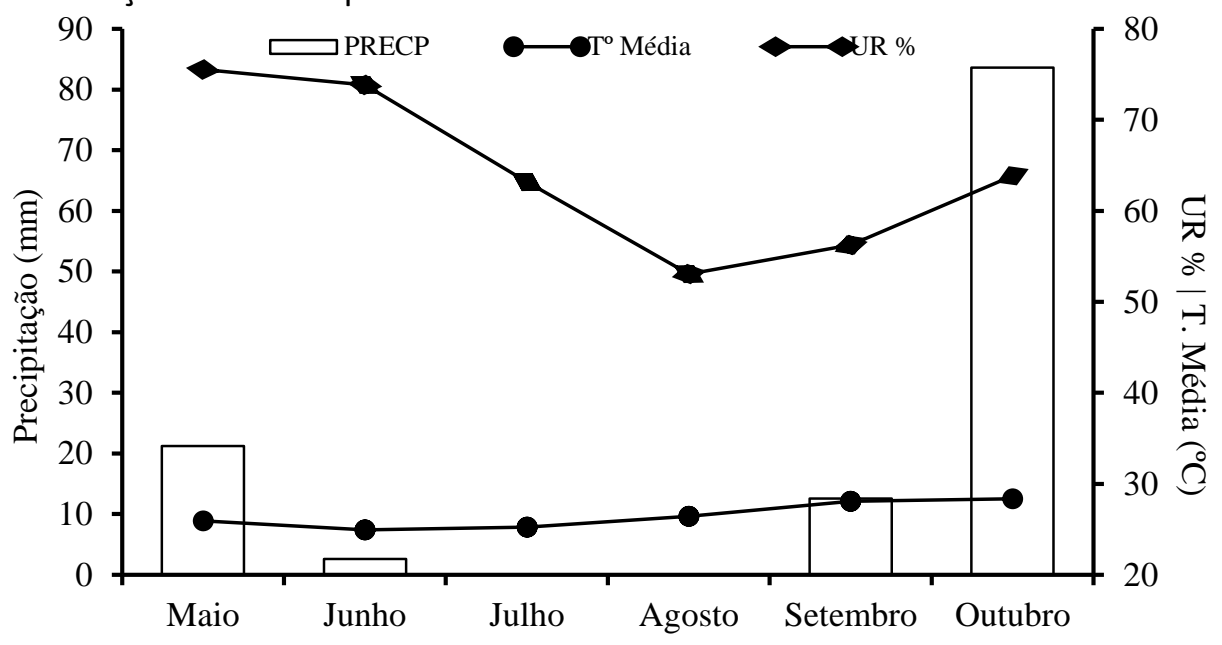


As avaliações foram realizadas aos 60 (10 corte), 105 (2 corte) e 150 (3 corte) dias após a semeadura (DAS). Os parâmetros avaliados foram: altura de plantas (AP - $m$ ), número de perfilhos vaso ${ }^{-1}$ (PERF), massa seca das folhas $\left(\mathrm{MSF}\right.$ - g.vaso ${ }^{-1}$ ), teor de $\mathrm{P}, \mathrm{Ca}$ e $\mathrm{Mg}$ na planta (g $\mathrm{kg}^{-1}$ ) e proteína bruta (\%).

A altura de planta foi determinada com auxílio de fita métrica medindo da base até o ápice das folhas. As plantas foram cortadas a 30 $\mathrm{cm}$ do solo e logo após foram acondicionadas em sacos de papel identificados e colocados em estufa com circulação de ar a 65ㄷ por 72 horas e após a secagem foram pesadas para determinação da MSF.

As amostras depois de trituradas foram submetidas à digestão sulfúrica segundo adaptação de Tedesco et al. (1995). A determinação de $\mathrm{N}$ foi feita pela destilação de Kjeldhal, os valores de $\mathrm{N}$ total foram multiplicados pelo fator 6,25 para obtenção da percentagem de PB. O P foi determinado com azul de molibdênio, sendo a leitura feita em um espectrofotômetro de massa. $O \quad P$ foi determinado com azul de molibdênio, sendo a leitura feita em um espectrofotômetro de massa. Os teores de $\mathrm{Ca}$ e $\mathrm{Mg}$ foram determinados pelo método de espectrofotometria de absorção atômica.

Os dados obtidos foram submetidos à análise de variância, e as médias comparadas pelo Teste de Tukey ( $p>0.05)$, utilizando o software SISVAR 5.3 (FERREIRA, 2008).

\section{Resultados e Discussão}

As fontes de fósforo com diferentes solubilidades e combinações mostraram significância ao nível de $5 \%$ de probabilidade em todos os parâmetros analisados. Para altura de planta, independente da fonte de fósforo $(P)$ e combinações, nos três cortes, ocorreu aumento em comparação com as plantas sob ausência de adubação (Tabela 2).

Tabela 2. Altura $(\mathrm{m})$ do capim Mombaça aos 60, 105 e 150 dias após semeadura sob fontes de fósforo de diferentes solubilidades

\begin{tabular}{lcccc}
\hline \multirow{2}{*}{ Fonte de P(1) } & 10 Corte & 20 Corte & 30 Corte & \multirow{2}{*}{ Média } \\
\cline { 2 - 4 } & 60 DAS* & 105 DAS & 150 DAS & \\
\hline Rejeito de Rocha (RJ) & $0,79 \mathrm{Bab}$ & $1,00 \mathrm{Ba}$ & $1,50 \mathrm{Aab}$ & $1,09 \mathrm{abcd}$ \\
Superfosfato triplo (ST) & $1,00 \mathrm{Aab}$ & $1,00 \mathrm{Aa}$ & $1,25 \mathrm{Aab}$ & $0,83 \mathrm{~cd}$ \\
Yoorin (YR) & $0,91 \mathrm{Aab}$ & $1,00 \mathrm{Aa}$ & $1,25 \mathrm{Aab}$ & $1,05 \mathrm{bcd}$ \\
RJ + ST (70\% e 30\%) & $1,13 \mathrm{Aab}$ & $1,00 \mathrm{Aa}$ & $1,25 \mathrm{Aab}$ & $1,12 \mathrm{abc}$ \\
RJ + ST (50\% e 50\%) & $1,05 \mathrm{Aab}$ & $1,00 \mathrm{Aa}$ & $1,25 \mathrm{Aab}$ & $1,10 \mathrm{abcd}$ \\
RJ + YR (70\% e 30\%) & $1,02 \mathrm{Bab}$ & $1,25 \mathrm{Ba}$ & $2,00 \mathrm{Aa}$ & $1,42 \mathrm{a}$ \\
RJ + YR (50\% e 50\%) & $0,83 \mathrm{Aab}$ & $1,00 \mathrm{Aa}$ & $1,25 \mathrm{Aab}$ & $1,02 \mathrm{bcd}$ \\
YR + ST (70\% e 30\%) & $1,01 \mathrm{Bab}$ & $1,00 \mathrm{Ba}$ & $1,75 \mathrm{Aa}$ & $1,25 \mathrm{ab}$ \\
YR + ST (50\% e 50\%) & $1,20 \mathrm{Ba}$ & $1,00 \mathrm{Ba}$ & $1,75 \mathrm{Aa}$ & $1,31 \mathrm{ab}$ \\
Sem adubação & $0,63 \mathrm{Bb}$ & $0,75 \mathrm{ABb}$ & $1,00 \mathrm{Ab}$ & $0,76 \mathrm{~d}$ \\
\hline Médias & $0,92 \mathrm{~B}$ & $0,95 \mathrm{~B}$ & $1,42 \mathrm{~A}$ & \\
\hline CV \% & & & & 22,72 \\
\hline
\end{tabular}

(1) RJ - Rejeito de rocha fosfática; ST - Superfosfato triplo; YR - Yoorin; RJ + ST (50\% e 50\%) - Rejeito de rocha fosfática + Superfosfato triplo; RJ + YR (50\% e 50\%) - Rejeito de rocha fosfática + Yoorin; YR + ST (50\% e 50\%) - Yoorin + Superfosfato triplo; Controle - Ausência de adubação fosfatada. Médias seguidas pelas mesmas letras maiúsculas nas colunas para fontes e minúsculas nas linhas para cortes, não diferem entre si ao nível de $5 \%$ pelo teste Tukey. *DAS Dias após a semeadura.

Aos 60 DAS o capim obteve a maior altura $(1,2$ m) quando submetido ao tratamento YR + ST $(50 \%$ e 50\%), havendo, portanto, uma contribuição significativa da fonte de fósforo mais solúvel, principalmente da solubilização do Yoorin em relação ao Rejeito de Rocha (RJ). O RJ, 
nos cortes posteriores, posteriormente, contribuiu mais efetivamente para o desenvolvimento da forrageira.

No segundo corte (105 DAS) todos os tratamentos apresentaram um desenvolvimento similar, não havendo diferença significativa entre eles, somente a testemunha apresentou menor altura se comparado com os demais tratamentos. Assim, pode-se enfatizar a importância do $\mathrm{P}$ para o desenvolvimento do Mombaça, pois mesmo havendo adubação suplementar a base de nitrogênio e potássio, o desenvolvimento da testemunha não foi satisfatório na ausência de $P$, pois o nutriente está diretamente ligado ao crescimento da planta e possui importância nas reações fotossintéticas e no metabolismo do carbono, processos pelos quais são fundamentais para assimilação e utilização do $\mathrm{N}$.

Já aos 150 DAS todos os tratamentos foram superiores à testemunha, em que RJ + YR (70\% e $30 \%)$, YR + ST (70\% e $30 \%)$ e YR + ST (50\% e 50\%) apresentaram as maiores alturas com 2,00; 1,75 e $1,75 \mathrm{~m}$, respectivamente. No RJ + YR (70\% e 30\%) o efeito foi ainda maior em função da combinação de fonte com baixa e alta solubilidade, de modo que atende à demanda da planta no curto e longo prazo. A superioridade da fonte com RJ é explicada pelo poder residual dos fertilizantes de baixa solubilidade, cuja liberação de fósforo ao solo ocorre de maneira gradual, porém em longo prazo (OLIVEIRA et al., 2012a), assim como a forrageira foi avaliada durante cinco meses simulando pastejo, essa característica de liberação gradual foi de extrema importância para manter a produção constante da forrageira.

Outro ponto importante é que a melhor resposta do capim foi nas combinações que possui o Yoorin, que tem $18 \%$ de $\mathrm{Ca}, 7 \%$ de $\mathrm{Mg}$, $0,1 \%$ de $\mathrm{B}, 0,05 \%$ de $\mathrm{Cu}, 0,3 \%$ de $\mathrm{Mn}, 10 \%$ de $\mathrm{Si}$ e $0,55 \%$ de $\mathrm{Zn}$. Isso é confirmado ao analisar as médias dos tratamentos ao final do experimento em que o RJ + YR (70\% e $30 \%$ ) obteve $1,42 \mathrm{~cm}$ de altura, que corresponde a $87 \%$ de acréscimo em altura em relação as plantas sem adubação.

Carneiro et al. (2017) ao avaliar fontes de fósforo (UFT Fértil, Fosfato Natural, Basifós e Superfosfato Simples) em Mombaça no Tocantins, obteve as maiores alturas $(0,75,0,75$, 0,70 e 0,72 m) para as fontes UFT Fértil, FN,
Basifós e SS respectivamente. Nesse estudo, a altura foi superior cerca de 44, 34, 30 e 36\% em relação a dose $0 \mathrm{~kg} \mathrm{ha}^{-1}$ de $\mathrm{P}_{2} \mathrm{O}_{5}$ para as fontes UFT Fértil, FN, Basifós e SS respectivamente.

Para número de perfilhos (Tabela 3), aos 60 DAS, melhores resultados foram ST, RJ + ST $(70 \%$ e $30 \%)$, RJ + ST (50\% e 50\%) e YR + ST (70\% e $30 \%)$, com 43,75, 40,0, 46,75 e 43,50 perfilhos, respectivamente. Importante ressaltar que os melhores resultados é na presença da fonte solúvel ST. As plantas sem adubação fosfatada tiveram somente 14,5 perfilhos, o que demostra a importância do $P$ no perfilhamento das pastagens. Estudo conduzido por Dias et al. (2015) também encontraram maior número de perfilhos em fontes mais solúveis, e explicam que isso ocorre em função da intensa atividade meristemática promovida pelo suprimento de fósforo na fase inicial do capim.

Para o segundo corte, os tratamentos ST, RJ + ST (70\% e 30\%), RJ + ST (50\% e 50\%) e YR + ST (70\% e 30\%), YR + ST (50\% e 50\%) produziram 67,$5 ; 61,5 ; 65,75 ; 64,75$ e 67 perfilhos, respectivamente. Já no terceiro corte, todas fontes e combinações de fósforo foram superiores à ausência de adubação (33,5 perfilhos), com exceção do rejeito de rocha (44 perfilhos). Os melhores tratamentos foram ST, YR, RJ + ST (70\% e 30\%), RJ + ST (50\% e 50\%), RJ + YR (70\% e 30\%), RJ + YR (50\% e 50\%), YR + ST (70\% e $30 \%)$ e YR + ST (50\% e $50 \%$ ) com 59; 57 ; 50,$25 ; 63,7 ; 52,25 ; 53,75 ; 52,5$ e 60,5 perfilhos. Os tratamentos com superfosfato triplo (ST) como fonte única de $P$ se destacou nos três cortes, porém as misturas onde continha essa mesma fonte como o RJ + ST (50\% e 50\%) obteve bons resultados, não havendo diferença, que confirma que os fosfatos com maior poder de reatividade são mais eficientes. Importante salientar que o período de avaliação foi cinco meses, tempo suficiente para as fontes solúveis de $P$ ainda obterem resposta positiva em perfilhos. Já quando são aliados a uma fonte com solubilidade menor, potencializam a disponibilidade gradual do $P$ no solo $e$ posteriormente, possivelmente, haverá uma maior produção de perfilhos. 
Tabela 3. Número de perfilhos de capim Mombaça aos 60, 105 e 150 dias após semeadura sob fontes de fósforo de diferentes solubilidades

\begin{tabular}{lcccc}
\hline \multirow{2}{*}{ Fonte P $^{(1)}$} & 10 Corte & 20 Corte & 30 Corte & \multirow{2}{*}{ Média } \\
\cline { 2 - 4 } & 60 DAS* & $105 \mathrm{DAS}$ & $150 \mathrm{DAS}$ & \\
\hline Rejeito de Rocha (RJ) & $24,00 \mathrm{Bab}$ & $33,25 \mathrm{ABbc}$ & $44,00 \mathrm{Aab}$ & $33,75 \mathrm{c}$ \\
Superfosfato triplo (ST) & $43,75 \mathrm{Ba}$ & $67,50 \mathrm{Aa}$ & $59,00 \mathrm{ABa}$ & $56,83 \mathrm{a}$ \\
Yoorin (YR) & $30,50 \mathrm{Bab}$ & $53,50 \mathrm{Aab}$ & $57,00 \mathrm{Aa}$ & $47,00 \mathrm{abc}$ \\
RJ + ST (70\% e 30\%) & $40,00 \mathrm{Ba}$ & $61,50 \mathrm{Aa}$ & $50,25 \mathrm{ABa}$ & $50,58 \mathrm{ab}$ \\
RJ + ST (50\% e 50\%) & $46,75 \mathrm{Ba}$ & $65,75 \mathrm{Aa}$ & $63,70 \mathrm{ABa}$ & $58,75 \mathrm{a}$ \\
RJ + YR (70\% e 30\%) & $22,00 \mathrm{Bab}$ & $42,00 \mathrm{Aab}$ & $52,25 \mathrm{Aa}$ & $38,75 \mathrm{bc}$ \\
RJ + YR (50\% e 50\%) & $22,00 \mathrm{Bab}$ & $41,25 \mathrm{Aabc}$ & $53,75 \mathrm{Aa}$ & $39,00 \mathrm{bc}$ \\
YR + ST (70\% e 30\%) & $43,50 \mathrm{Ba}$ & $64,75 \mathrm{Aa}$ & $52,50 \mathrm{ABa}$ & $53,58 \mathrm{a}$ \\
YR + ST (50\% e 50\%) & $41,25 \mathrm{Bab}$ & $67,00 \mathrm{Aa}$ & $60,50 \mathrm{Aa}$ & $56,25 \mathrm{a}$ \\
Sem adubação & $14,5 \mathrm{Bb}$ & $14,00 \mathrm{Bc}$ & $33,50 \mathrm{Ab}$ & $11,33 \mathrm{~d}$ \\
\hline Médias & $32,82 \mathrm{~B}$ & $51,07 \mathrm{~A}$ & $52,65 \mathrm{~A}$ & \\
\hline CV & & & & \\
\hline
\end{tabular}

CV \%
(1) RJ - Rejeito de rocha fosfática; ST - Superfosfato triplo; YR - Yoorin; RJ + ST (50\% e 50\%) - Rejeito de rocha fosfática + Superfosfato triplo; RJ + YR (50\% e 50\%) - Rejeito de rocha fosfática + Yoorin; YR + ST (50\% e 50\%) - Yoorin + Superfosfato triplo; Controle - Ausência de adubação fosfatada. Médias seguidas pelas mesmas letras maiúsculas nas colunas para fontes e minúsculas nas linhas para cortes, não diferem entre si ao nível de $5 \%$ pelo teste Tukey. ${ }^{*}$ DAS Dias após a semeadura.

Utilizando o rejeito de rocha separadamente não apresentou bom rendimento em número de perfilhos se comparado com as demais fontes, isso corrobora com Lima et al. (2007) que descrevem que a resposta inicial na implantação de pastagens é maior em fontes de $\mathrm{P}$ solúveis. Cecato et al. (2008) com diferentes fontes de P, observaram que fontes com maior solubilidade como Superfosfato simples e posteriormente o Yoorin, proporcionaram um maior incremento foliar e posteriormente maior quantidade de perfilhos. Ainda destaca que o fósforo tem maior influência no perfilhamento do que no alongamento foliar em gramíneas, pois desempenha papel importante nas características morfológicas e produção do capim como visto no presente trabalho.

Na produção de massa seca do capim (Tabela 4), o tratamento YR + ST (50\% e 50\%) mostrou-se mais eficiente em comparação aos demais tratamentos nos três cortes realizados. As plantas obtiveram neste tratamento $57,35 \mathrm{~g}$ (10 corte), $112,48 \mathrm{~g}$ (2을 corte), $236,19 \mathrm{~g}$ de MS (3을 corte), e uma média geral de 135,34 g que representa $326 \%$ a mais de massa seca (MS) em relação as plantas com ausência de P. Devido o período do experimento ser relativamente curto, a maior MS no YR + ST (50\% e 50\%) pode ser explicado pela alta solubilidade, como comentado por Oliveira et al. (2012a), em que as fontes mais solúveis disponibilizam grande quantidade de $P$ nos primeiros meses após o plantio proporcionando melhor desenvolvimento inicial, que reflete em biomassa nas pastagens. No entanto, aos 150 DAS o rejeito de rocha foi um dos que mais elevou a MS do capim com 179,66 g. Isso demostra a importância de fontes pouco solúveis, de forma isoladas ou em combinação, para períodos mais prolongados de pastejo. 
Tabela 4. Produção de Massa Seca de capim Mombaça aos 60, 105 e 150 dias após semeadura sob fontes de fósforo de diferentes solubilidades

\begin{tabular}{lcccc}
\hline \multirow{2}{*}{ Fonte P } & 19 Corte & 20 Corte & 30 Corte & \multirow{2}{*}{ Média } \\
\cline { 2 - 4 } & 60 DAS* & $105 \mathrm{DAS}$ & $150 \mathrm{DAS}$ & \\
\hline Rejeito de Rocha (RJ) & $38,96 \mathrm{Babcd}$ & $59,75 \mathrm{Bab}$ & $179,66 \mathrm{Aab}$ & $92,79 \mathrm{~b}$ \\
Superfosfato triplo (ST) & $37,93 \mathrm{Babcd}$ & $63,81 \mathrm{Bab}$ & $158,21 \mathrm{Aab}$ & $82,90 \mathrm{~b}$ \\
Yoorin (YR) & $13,88 \mathrm{Bcd}$ & $58,58 \mathrm{Bab}$ & $183,19 \mathrm{Aab}$ & $85,22 \mathrm{~b}$ \\
RJ + ST (70\% e 30\%) & $47,04 \mathrm{Babc}$ & $76,16 \mathrm{Bab}$ & $172,61 \mathrm{Aab}$ & $92,35 \mathrm{~b}$ \\
RJ + ST (50\% e 50\%) & $52,01 \mathrm{Bab}$ & $74,76 \mathrm{Bab}$ & $136,57 \mathrm{Aab}$ & $87,78 \mathrm{~b}$ \\
RJ + YR (70\% e 30\%) & $19,10 \mathrm{Bbcd}$ & $68,73 \mathrm{Bab}$ & $165,96 \mathrm{Aab}$ & $74,76 \mathrm{~b}$ \\
RJ + YR (50\% e 50\%) & $8,71 \mathrm{Cd}$ & $60,82 \mathrm{Bab}$ & $142,44 \mathrm{Aab}$ & $70,65 \mathrm{bc}$ \\
YR + ST (70\% e 30\%) & $50,11 \mathrm{Bab}$ & $61,19 \mathrm{Bab}$ & $147,02 \mathrm{Aab}$ & $86,11 \mathrm{~b}$ \\
YR + ST (50\% e 50\%) & $57,35 \mathrm{Ba}$ & $112,48 \mathrm{Ba}$ & $236,19 \mathrm{Aa}$ & $135,34 \mathrm{a}$ \\
Sem adubação & $6,74 \mathrm{Bd}$ & $20,37 \mathrm{ABb}$ & $68,02 \mathrm{Ab}$ & $31,71 \mathrm{c}$ \\
\hline Média & $33,18 \mathrm{C}$ & $60,84 \mathrm{~B}$ & $158,88 \mathrm{~A}$ & \\
\hline CV \% & & & 34,71
\end{tabular}

(1) RJ - Rejeito de rocha fosfática; ST - Superfosfato triplo; YR - Yoorin; RJ + ST (50\% e 50\%) - Rejeito de rocha fosfática + Superfosfato triplo; RJ + YR (50\% e 50\%) - Rejeito de rocha fosfática + Yoorin; YR + ST (50\% e 50\%) - Yoorin + Superfosfato triplo; Controle - Ausência de adubação fosfatada. Médias seguidas pelas mesmas letras maiúsculas nas colunas para fontes e minúsculas nas linhas para cortes, não diferem entre si ao nível de $5 \%$ pelo teste Tukey. *DAS Dias após a semeadura.

A combinação de RJ + ST ( $50 \%$ e $50 \%$ ) também foi eficiente na produção de massa seca com $52,01 \mathrm{~g} \mathrm{vaso}^{-1}$ no 1 을 Corte, assim como ocorreu na produção de perfilhos (Tabela 3). Já na média geral dos três cortes, a produção de massa seca foi de $87,78 \mathrm{~g}$ vaso $^{-1}$, ou seja, $176 \%$ de acréscimo em relação ao controle.

Fleitas et al. (2018) testaram fontes com diferentes solubilidades no capim-convert HD364 em Latossolo Vermelho distroférrico e Neossolo Quartzarênico e observaram efeitos das fontes FH Pastagem (FH, solubilidade mista) e Fosfato Natural Reativo (FNR, solubilidade lenta em ácido). As fontes de solubilidade rápida, lenta e mista influenciaram na estrutura morfológica da planta. Verificaram também que a produção total de matéria seca foi mais eficiente nos tratamentos com as fontes de maior solubilidade, como o superfosfato triplo, fosfato natural reativo e a mistura entre eles, principalmente no primeiro, terceiro e quarto cortes.

Quanto aos efeitos das fontes de fósforo com diferentes solubilidades no teor de fósforo na planta, a influência foi principalmente aos 105 e 150 DAS (Tabela 5a). No primeiro corte não houve diferença entre as fontes de $\mathrm{P}$ e o controle. Já aos 105 DAS, as fontes RJ+YR (50\% e 50\%), RJ+ST ( $50 \%$ e $50 \%)$, e YR+ST ( $70 \%$ e $30 \%$ ) foram superiores às demais, com teores de 0,66, 0,63 e $0,59 \mathrm{~g} \mathrm{~kg}^{-1}$ de $P$, respectivamente, sendo estas em média $50 \%$ superior a ausência de $P$. Na média dos cortes, a fonte YR obteve o menor teor de $\mathrm{P}$, com $0,25 \mathrm{~g} \mathrm{~kg}^{-1}$, que resulta em $152 \%$ menor que as melhores fontes. 
Tabela 5. Teores de fósforo (a), cálcio (b) e magnésio (c) em plantas de capim Mombaça aos 60, 105 e 150 dias após semeadura sob fontes de fósforo de diferentes solubilidades.

\begin{tabular}{|c|c|c|c|c|}
\hline \multirow{2}{*}{ Fonte $\mathrm{P}^{(1)}$} & 1을 Corte & 2ㅇ Corte & 3을 Corte & \multirow{2}{*}{ Média } \\
\hline & 60 DAS* & 105 DAS & 150 DAS & \\
\hline \multicolumn{5}{|c|}{ Fósforo (a) } \\
\hline Rejeito de Rocha (RJ) & $0,41 \mathrm{Ab}$ & $0,37 \mathrm{Bb}$ & $0,59 \mathrm{Aa}$ & $0,46 a$ \\
\hline Superfosfato triplo (ST) & $0,45 \mathrm{Aa}$ & $0,38 \mathrm{Ba}$ & $0,31 \mathrm{Bb}$ & $0,38 a b$ \\
\hline Yoorin (YR) & $0,43 \mathrm{Aa}$ & $0,25 \mathrm{Cc}$ & $0,32 \mathrm{Bb}$ & $0,33 \mathrm{~b}$ \\
\hline RJ + ST (70\% e 30\%) & 0,39 Аа & $0,37 \mathrm{Ba}$ & 0,31 Ba & $0,35 b$ \\
\hline RJ + ST (50\% e 50\%) & $0,47 \mathrm{Ab}$ & 0,63 Аa & $0,21 \mathrm{Cc}$ & $0,44 a$ \\
\hline RJ + YR (70\% e 30\%) & $0,29 A b$ & 0,50 Ba & $0,21 \mathrm{Cb}$ & $0,33 b$ \\
\hline RJ + YR (50\% e 50\%) & $0,37 \mathrm{Ab}$ & $0,66 \mathrm{Aa}$ & $0,25 \mathrm{Cc}$ & $0,43 a$ \\
\hline YR + ST (70\% e 30\%) & $0,37 \mathrm{Ab}$ & $0,52 \mathrm{Ba}$ & $0,40 \mathrm{Bb}$ & $0,41 a b$ \\
\hline YR + ST (50\% e 50\%) & $0,33 \mathrm{Ab}$ & 0,59 Аa & $0,30 \mathrm{Bb}$ & $0,41 a b$ \\
\hline Sem adubação & $0,32 \mathrm{Ab}$ & $0,42 \mathrm{Ba}$ & $0,44 \mathrm{Bab}$ & $0,39 a b$ \\
\hline CV (\%) & & & & 20,54 \\
\hline \multicolumn{5}{|c|}{ Cálcio (b) } \\
\hline Rejeito de Rocha (RJ) & $5,8 \mathrm{Ac}$ & $10,7 \mathrm{Bb}$ & $18,6 \mathrm{Ba}$ & $11,70 \mathrm{~b}$ \\
\hline Superfosfato triplo (ST) & $5 A b$ & $8,8 \mathrm{Bb}$ & $13,9 \mathrm{Ba}$ & $9,23 \mathrm{~b}$ \\
\hline Yoorin (YR) & $4,8 \mathrm{Ab}$ & $9 \mathrm{Bb}$ & $14 \mathrm{Ba}$ & $9,27 \mathrm{~b}$ \\
\hline RJ + ST (70\% e 30\%) & $6,14 \mathrm{Ab}$ & $6,23 \mathrm{Bb}$ & $16,08 \mathrm{Ba}$ & $9,51 b$ \\
\hline RJ + ST (50\% e 50\%) & $8,5 \mathrm{Ab}$ & $7 \mathrm{Bb}$ & 17,1 Ba & $10,87 b$ \\
\hline RJ + YR (70\% e 30\%) & $8,86 \mathrm{Ab}$ & $6,84 \mathrm{Bb}$ & $17,31 \mathrm{Ba}$ & $11,00 \mathrm{~b}$ \\
\hline RJ + YR (50\% e 50\%) & $8,7 \mathrm{Ab}$ & 7,8 Bb & $17,2 \mathrm{Ba}$ & $11,23 b$ \\
\hline YR + ST (70\% e 30\%) & $6,91 \mathrm{Ab}$ & $17,12 \mathrm{Aa}$ & $20,16 \mathrm{Aa}$ & 14,79ab \\
\hline YR + ST (50\% e 50\%) & $8,2 \mathrm{Ab}$ & $22,32 \mathrm{Aa}$ & $20,8 \mathrm{Aa}$ & $17,07 a$ \\
\hline Sem adubação & $7 \mathrm{Ab}$ & 7,7 Bb & $10,3 \mathrm{Ca}$ & $8,33 \mathrm{~b}$ \\
\hline CV (\%) & & & & 18,36 \\
\hline \multicolumn{5}{|c|}{ Magnésio (c) } \\
\hline Rejeito de Rocha (RJ) & $2,4 \mathrm{Ab}$ & $2,4 \mathrm{Bb}$ & 7,8 Aa & $4,20 \mathrm{~b}$ \\
\hline Superfosfato triplo (ST) & $2,3 \mathrm{Ab}$ & $2,7 \mathrm{Bb}$ & 6,9 Aa & $3,97 \mathrm{~b}$ \\
\hline Yoorin (YR) & $3 \mathrm{Ab}$ & $2,7 \mathrm{Bb}$ & $8 \mathrm{Aa}$ & $4,57 \mathrm{~b}$ \\
\hline RJ + ST (70\% e 30\%) & $2,13 \mathrm{Ab}$ & $2,38 \mathrm{Bb}$ & 7,42 Aa & $3,97 \mathrm{~b}$ \\
\hline RJ + ST (50\% e $50 \%)$ & $2,9 \mathrm{Ab}$ & $2,5 \mathrm{Bb}$ & $7 \mathrm{Aa}$ & $4,13 \mathrm{~b}$ \\
\hline RJ + YR (70\% e 30\%) & $2,50 \mathrm{Ab}$ & $2,29 \mathrm{Bb}$ & 6,89 Aa & $3,89 \mathrm{~b}$ \\
\hline RJ + YR (50\% e 50\%) & $2,5 \mathrm{Ab}$ & $2,7 \mathrm{Bb}$ & 7,4 Aa & $4,20 \mathrm{~b}$ \\
\hline YR + ST (70\% e 30\%) & $2,44 \mathrm{Ab}$ & $5,40 \mathrm{Aa}$ & 6,19 Aa & $4,67 \mathrm{~b}$ \\
\hline YR + ST (50\% e 50\%) & $2,6 \mathrm{Ab}$ & 7,2 Aa & 7,5 Aa & 5,77 a \\
\hline Sem adubação & 2,3 Aa & $2,5 \mathrm{Bb}$ & 4,8 Aa & $3,2 \mathrm{c}$ \\
\hline CV (\%) & & & & 19,98 \\
\hline
\end{tabular}

${ }^{(1)}$ RJ - Rejeito de rocha fosfática; ST - Superfosfato triplo; YR - Yoorin; RJ + ST (50\% e 50\%) - Rejeito de rocha fosfática + Superfosfato triplo; RJ + YR (50\% e 50\%) - Rejeito de rocha fosfática + Yoorin; YR + ST (50\% e 50\%) - Yoorin + Superfosfato triplo; Controle - Ausência de adubação fosfatada. Médias seguidas pelas mesmas letras maiúsculas nas colunas para fontes e minúsculas nas linhas para cortes, não diferem entre si ao nível de $5 \%$ pelo teste Tukey. *DAS Dias após a semeadura.

Aos 150 DAS, a fonte que mais se destacou foi a RJ, com 0,59 $\mathrm{g} \mathrm{kg}^{-1}$ de $\mathrm{P}, 34,09 \%$. Num comparativo com os demais tratamentos a fonte RJ foi em média 110,71\% maior. Benício (2012) também encontrou maior teor de $\mathrm{P}$ em plantas com RJ e fosfato parcialmente acidulado, principalmente a partir do segundo corte. Isso ocorre devido a liberação gradual de $\mathrm{P}$ e ao desenvolvimento da forrageira. Ainda segundo o autor, no primeiro corte provavelmente o tempo limitou a liberação de $\mathrm{P}$ do RJ para o solo, que influenciou na menor biomassa da planta. Já na segunda avaliação a quantidade de $P$ liberada pela foi maior, que proporcionou maior absorção 
do elemento pela planta. A quantidade absorvida pela planta, somada ao $\mathrm{P}$ já estocado nos tecidos, fez com que, na segunda avaliação as quantidades fossem superiores à primeira. A maior concentração de $\mathrm{P}$ na parte área durante $\mathrm{o}$ terceiro corte pode ser devido à idade da planta e a disponibilidade do fósforo no solo.

Em estudo com fontes $\mathrm{P}$ (superfosfato triplo, fosfato de Arad, fosfato natural de Araxá e mistura superfosfato triplo + fosfato de Arad na relação (1:1) em Brachiaria brizantha, Costa (2008) relatou que o teor de $P$ na forrageira foi influenciado, significativamente, pelas fontes de $P$ de maior solubilidade. Resultados semelhantes foram relatados por Oliveira et al. (2012b), em que o Superfosfato simples apresentou maior teor de $\mathrm{P}$ foliar, do que o fosfato natural de Arad e a testemunha. De maneira geral, sabe-se que o $\mathrm{P}$ é o elemento mineral que mais onera o custo dos suplementos minerais para bovinos, sendo que, quanto maior o teor deste elemento na matéria seca das forrageiras, menor será o consumo pelos bovinos via suplementação mineral. Sendo assim, é de suma importância a maior capacidade de assimilação e concentração de $\mathrm{P}$ na parte aérea pela planta forrageira.

Para os teores de cálcio (Tabela 5b), não houve diferença entre os tratamentos para o primeiro corte. No segundo corte, aos 105 DAS, o YR + ST (50\% e 50\%) e YR + ST (70\% e 30\%), em que o YR + ST (50\% e $50 \%)$ sobressaiu aos demais tratamentos com $22,32 \mathrm{~g} \mathrm{~kg}^{-1}$, superior em $288 \%$ à ausência de P. Já aos 150 DAS, o YR + ST (50\% e $50 \%$ ) e YR + ST (70\% e $30 \%$ ), com 20,8 e 20,16 g $\mathrm{kg}^{-1}$, respectivamente, obtiveram maiores concentrações de Ca na folha. Os maiores teores de Ca são por possuírem o elemento na composição destas fontes (ST - 12\% de Ca, YR $18 \%$ de $\mathrm{Ca}$ e RJ com 11,3\% de $\mathrm{CaO}$ ), e demostra a eficácia da planta em assimila-lo e mantê-lo na estrutura, aumentando o teor nutricional.

Quanto ao Magnésio (Tabela $5 \mathrm{c}$ ), assim como para o $\mathrm{P}$ e $\mathrm{Ca}$, o primeiro corte não apresentou diferença entre os tratamentos. Já no segundo corte, houve crescente elevação no teor de $\mathrm{Mg}$ nas folhas no YR + ST (50\% e 50\%) e YR + ST (70\% e $30 \%)$, em que o YR + ST (50\% e $50 \%$ ) saiu de 2,6 (60 DAS) para 7,2 g kg-1 (105 DAS). Isso resultado pode ser devido a presença do elemento na fonte Yorin ( $7 \%$ de $\mathrm{Mg}$ ) e posteriormente pela eficiência da forrageira em absorver, mesmo que em pequena quantidade e utiliza-lo para aumentar o potencial nutritivo.

Aos 150 DAS não houve diferença entre os tratamentos com $\mathrm{P}$, quem em média foram superiores cerca de $35 \%$ em relação ao controle. Para Werner (1996) em plantas de capimcolonião, os resultados situaram na faixa de 1 a 5 $\mathrm{g} \mathrm{kg}^{-1}$ de $\mathrm{Mg}$, que corrobora com Primavesi et al. (2004) com capim-coastcross, observaram teores de 1,8 a $2,7 \mathrm{~g} \mathrm{~kg}^{-1}$. No entanto, estes teores podem variar em função da espécie e no caso do Mombaça em estudo, os valores de Mg encontrase em teores acima dos observados para colonião e coastcross, que corrobora com resultado obtido por Tebaldi et al. (2000).

Para os teores de Proteína Bruta (PB), aos 60 dias, os tratamentos RJ e YR se destacaram em comparação as demais fontes, com valores de 20 e $20,7 \%$ de $P B, 17,4 \%$ superior a ausência de $P$ (Tabela 6). 
Tabela 6. Teor de Proteína bruta em capim Mombaça aos 60, 105 e 150 dias após semeadura sob fontes de fósforo de diferentes solubilidades.

\begin{tabular}{|c|c|c|c|c|}
\hline \multirow{2}{*}{ Fonte $\mathrm{P}^{(1)}$} & 10 Corte & 20 Corte & 3을 Corte & \multirow{2}{*}{ Média } \\
\hline & 60 DAS* & 105 DAS & 150 DAS & \\
\hline Rejeito de Rocha (RJ) & $20 \mathrm{Aa}$ & $21,5 \mathrm{Aa}$ & $20 \mathrm{Aa}$ & $20,50 \mathrm{a}$ \\
\hline Superfosfato triplo (ST) & $14,8 \mathrm{Bb}$ & 18,9 Aab & $12 \mathrm{Bb}$ & $15,23 \mathrm{~b}$ \\
\hline Yoorin (YR) & $20,7 \mathrm{Aa}$ & $15,1 \mathrm{Bb}$ & $12,7 \mathrm{Bb}$ & $16,17 \mathrm{~b}$ \\
\hline RJ + ST (70\% e 30\%) & $12,5 \mathrm{Bb}$ & $12,8 \mathrm{Bb}$ & $16,9 \mathrm{Ab}$ & $14,06 \mathrm{~b}$ \\
\hline RJ + ST (50\% e 50\%) & $14,2 \mathrm{Bb}$ & $13 \mathrm{Bb}$ & $15,8 \mathrm{Ab}$ & $14,33 \mathrm{~b}$ \\
\hline RJ + YR (70\% e 30\%) & $17,1 \mathrm{Bb}$ & $15,6 \mathrm{Bb}$ & $12,9 \mathrm{Ab}$ & $15,20 b$ \\
\hline RJ + YR (50\% e 50\%) & $16,8 \mathrm{Bb}$ & $16,1 \mathrm{Bb}$ & $16,3 \mathrm{Ab}$ & $16,40 \mathrm{~b}$ \\
\hline YR + ST (70\% e 30\%) & $17,9 \mathrm{Bb}$ & $15,2 \mathrm{Bb}$ & $14,8 \mathrm{Ab}$ & $15,96 b$ \\
\hline YR + ST (50\% e 50\%) & $12,7 \mathrm{Bb}$ & $12,8 \mathrm{Bb}$ & $10,9 \mathrm{Ab}$ & $12,13 b$ \\
\hline Controle & $17,1 \mathrm{BAb}$ & $18 \mathrm{Aab}$ & $19,9 \mathrm{Aa}$ & $18,33 a b$ \\
\hline Média & $16,61 \mathrm{~A}$ & $16,49 \mathrm{~A}$ & $15,37 \mathrm{~A}$ & \\
\hline CV \% & & & & 16,23 \\
\hline
\end{tabular}

No segundo corte, a fonte RJ foi superior com $21,5 \%$ de PB, seguido do ST com 18,9\% e ausência de $P$ com $18 \%$ de PB. Aos 150 DAS, notou-se um resultado semelhante em que a fonte RJ obteve $20 \%$ de PB. Na média geral a fonte RJ obteve o teor de PB (20,5\%), seguido do tratamento com ausência de $P$ (18,33\%). De modo, as fontes de $P$ não tiveram influência significativa no teor de PB, com exceção do RJ, que não diferenciou da ausência de $P$. Isso demostra que os efeitos foram do nitrogênio aplicados em cobertura através do Sulfato de amônio (100 kg ha ${ }^{-1}$ de N).

Os resultados demonstram que a adubação fosfatada com solubilidades diferentes, proporcionam respostas positivas para maioria das características morfológicas e nutricionais do capim Megathyrsus maximus cv. Mombaça. A interação das fontes com alta e baixa solubilidades, pode melhorar a eficiência da adubação, atendendo as necessidades da planta no período de curto e longo prazo.

\section{Conclusões}

Os tratamentos utilizados com intuito de fornecer fósforo as plantas, independente da fonte e mistura, promoveram incrementos positivos nas características agronômicas e nutricionais da forrageira Megathyrsus maximus cv. Mombaça. Entretanto, as combinações de fontes fosfatadas, tais como YR + ST (50\% e 50\%),
$Y R+S T(70 \%$ e $30 \%)$ e RJ + YR (50\% e $50 \%)$, promoveram os maiores resultados nas características agronômicas em relação a aplicação destas separadamente.

- Nos teores nutricionais, para o $\mathrm{P}$, as melhores fontes RJ, RJ + ST ( $50 \%$ e $50 \%$ ) e RJ + YR (50\% e $50 \%)$. No Ca foi YR + ST (50\% e $50 \%)$ e para $\mathrm{Mg}$ foi ST ( $50 \%$ e $50 \%$ ).

\section{Referências}

BENÍCIO, L.P.F. Rejeitos de Rochas fosfáticas no desenvolvimento e no teor de nutrientes em Brachiaria Brizantha. 2012. 79f. Dissertação (Mestrado em Produção Vegetal) - Universidade Federal do Tocantins, Gurupi.

CARNEIRO, J. S. S.; SILVA, P. S. S.; SANTOS, A. C. M.; FREITAS, G. A.; SILVA, R. R. Response of grass Mombasa under the effect of sources and doses of phosphorus in the fertilization formation. Journal of Bioenergy and Food Science, v.4, p.1225, 2017. https://doi.org/10.18067/ibfs.v4i1.117

CECATO, U.; SKROBOT, V. D.; FAKIR, G. R.; BRANCO, A. F.; GALBEIRO, S.; GOMES, J. A. N. Perfilhamento e características estruturais do capim - Mombaça, adubado com fontes de fósforo, em pastejo. Acta Scientiarum. Animal Sciences, v.30, n.1, p.1-7, 2008. https://doi.org/10.4025/actascianimsci.v30i1.359 $\underline{3}$ 
COSTA, N.L.; JANK, L.; MAGALHÃES, J.A.; FOGAÇA, F.H.S.; RODRIGUES, A.N.A.; SANTOS, F.J.S. Acúmulo de forragem e morfogênese de Megathyrsus maximus cv. Mombaça sob níveis de fósforo. PUBVET Medicina veterinária e Zootecnia, v.11, n.11, p.1163-1168, 2017. https://doi.org/10.22256/pubvet.v11n11.1163$\underline{1168}$

COSTA, S.E.V.G.A.; FURTINI NETO, A. E.; RESENDE, Á.V.; SILVA, T.O.; SILVA T.R. Crescimento e nutrição da Braquiária em função de fontes de fósforo. Ciência e Agrotecnologia, v.32, n.5, p.1419-1427, 2008. https://doi.org/10.1590/S1413$\underline{70542008000500010}$

DIAS, D.G.; PEGORARO, R.F.; ALVES, D.D.; PORTO, E.M.V.; SANTOS, J.A. Produção do capim Piatã submetido a diferentes fontes de fósforo. Revista Brasileira de Engenharia Agrícola e Ambiental, v.19, n.4, p.330-335, 2015. https://doi.org/10.1590/1807-

1929/agriambi.v19n4p330-335

FERREIRA, D.F. Sisvar: um programa para análises e ensino de estatística. Revista Symposium, v. 6, p. 36-41, 2008.

FERNANDES, M.S. Nutrição mineral de plantas. Viçosa : Sociedade Brasileira de Ciência do Solo, 2006. 432p.

FLEITAS, A.C.; PAIVA, L.M.; FERNANDES, H.J.; DUARTE, C.F.D.; FALCÃO, K.R.S.; BISERRA, T.T. Características morfogênicas do capim-convert HD364 ${ }^{\circledR}$ adubado com diferentes fontes de fósforo. Revista Agrarian, v.11, n.39, p. 59-67, 2018.

https://doi.org/10.30612/agrarian.v11i39.5362

KORNDÖRFER, G.H.; LARA-CABEZAS, W.A.; HOROWITZ, N. Eficiência agronômica de fosfatos naturais reativos na cultura do milho. Scientia agrícola, v.56, n.2, p.391-396, 1999. https://doi.org/10.1590/S0103-

$\underline{90161999000200019}$

LIMA, S. O.; FIDELIS, R. R.; COSTA, S. J. Avaliação de fontes e doses de fósforo no estabelecimento de Brachiaria brizanta cv. Marandú no sul do Tocantins. Pesquisa Agropecuária Tropical, v.37, n.2, p. 100-105, 2007.
MALAVOLTA, E. Elementos de nutrição mineral de plantas. São Paulo: Agronômica Ceres, 1980. $251 \mathrm{p}$.

MELO, M.P; LIMA, R.C.P.; FREITAS, G.A.; LIMA, S.O. Fontes e doses de fósforo na produção de Panicum maximum cv. Massai. Tecnologia \& Ciência Agropecuária, v.12, n.2, p.25-35, 2018a.

MELO, M.P.; LIMA, R.C.P.; FREITAS, G.A.; OLIVEIRA, L.B.; LIMA, S.O. Produção do capim Piatã submetido a fontes e doses de fósforo. Tecnologia \& Ciência Agropecuária, v.12, n.3, p.15-23, 2018b.

OLIVEIRA, T.C.; SILVA, J.; SALGADO, F.H.M.; SOUSA, S.A.; FIDELIS, R.R. Eficiência e resposta à aplicação de fósforo em feijão comum em solos de cerrado. Revista Verde de Agroecologia e Desenvolvimento Sustentável, v.7, n.1, p.16 24, 2012a.

OLIVEIRA, S. B.; CAIONE, G.; CAMARGO, M. F. NATALI, A.; OLIVEIRA, B.; SANTANA, L. Fontes de fósforo no estabelecimento e produtividade de forrageiras na região de Alta Floresta - MT. Global Science and Technology, v.5, n.1, p.1-10, 2012b.

OLIVEIRA, C.M.B.; GATIBONI, L.C.; ERNANI, P.R.; BOITT, G.; BRUNETTO, G. Capacidade de predição da disponibilidade de fósforo em solo com aplicação de fosfato solúvel e natural. Científica, v.43, n.4, p.413-419, 2015. https://doi.org/10.15361/1984-

5529.2015v43n4p413-419

PRIMAVESI, A.C.; PRIMAVESI, O.; CORRÊA, L.A.; CANTARELLA, H.; SILVA, A.G.; FREITAS, A.R; VIVALDI, L.F. Adubação nitrogenada em capimcoastcross: efeitos na extração de nutrientes e recuperação aparente do nitrogênio. Revista Brasileira Zootecnia, v.33, n.1, p.68-78, 2004. https://doi.org/10.1590/S1516$\underline{35982004000100010}$

TEBALDI, F.L.H.; SILVA, J.F.C.; VASQUEZ, H.M.; THIEBAUT, J.T.L. Composição mineral das pastagens das regiões norte e noroeste do Estado do Rio de Janeiro: matéria orgânica, alumínio e $\mathrm{pH}$ dos solos. Revista Brasileira de Zootecnia, v.29, n.2, p.382-386, 2000. https://doi.org/10.1590/\$1516$\underline{35982000000200009}$ 
TEDESCO, M.J.; GIANELLO, C.; BISSANI, C.A.; BOHNEN, H.; VOLKWEISS, S.J. Análise de solo, plantas e outros materiais. 2. ed. Porto Alegre: Universidade Federal de Rio Grande do Sul, 1995.

TEIXEIRA, S.O.; TEIXEIRA, R.O.; SANTOS, V.B.; CARVALHO, M.A.C.; YAMASHITA, O.M. Doses de fósforo e nitrogênio na produção de Brachiaria hibrida cv. Mulato II. Revista Ceres, v. 65, n.1, p.28-34, 2018. https://doi.org/10.1590/0034$\underline{737 \times 201865010005}$

TOSCANI, R.G.S.; CAMPOS, J.E.G. Uso de pó de basalto e rocha fosfatada como remineralizadores em solos intensamente intemperizados. Geociências, v.36, n.2, p.259274, 2017. https://doi.org/10.5016/geociencias.v36i2.11472

VAN STRAATEN, P. Farming with rocks and minerals: challenges and opportunities. Anais da Academia Brasileira de Ciências, v.78, n.4, p.731747, 2006. https://doi.org/10.1590/50001$\underline{37652006000400009}$

VILELA, L.; SOARES, W.V.; SOUSA, D.M.G.; MACEDO, M.C.M. Calagem e adubação para pastagens. In: SOUSA, D.M.G.; LOBATO, E. (Ed.). Cerrado: correção do solo e adubação. Planaltina: Embrapa Cerrados, 2007. p.367-382.

WERNER, J. C.; KALIL, E. B.; GOMES, E. P.; PEDREIRA, J. V. S.; ROCHA, G. L.; SARTINI, H. J. Competição de adubos fosfatados. Boletim de Indústria Animal, v.25, p.139-149, 1996. 